\title{
The role of 5-lipoxygenase in the pathophysiology of COVID-19 and its therapeutic implications
}

\author{
Nohora Cristina Ayola-Serrano ${ }^{1}$ - Namrata Roy ${ }^{2}$ - Zareena Fathah ${ }^{3} \cdot$ Mohammed Moustapha Anwar $^{4}$. \\ Bivek Singh ${ }^{5} \cdot$ Nour Ammar $^{6} \cdot$ Ranjit Sah $^{7} \cdot$ Areej Elba $^{6} \cdot$ Rawan Sobhi Utt $^{8} \cdot$ Samuel Pecho-Silva ${ }^{9,10,11}$. \\ Alfonso J. Rodriguez-Morales ${ }^{9,11,12,13} \cdot$ Kuldeep Dhama $^{14} \cdot$ Sadeq Quraishi ${ }^{15}$
}

Received: 15 December 2020 / Revised: 21 April 2021 / Accepted: 15 May 2021 / Published online: 4 June 2021

(c) The Author(s), under exclusive licence to Springer Nature Switzerland AG 2021

\begin{abstract}
Severe acute respiratory syndrome coronavirus 2 (SARS-CoV-2) infection, known as coronavirus disease 2019 (COVID-19) causes cytokine release syndrome (CRS), leading to acute respiratory distress syndrome (ARDS), acute kidney and cardiac injury, liver dysfunction, and multiorgan failure. Although several studies have discussed the role of 5-lipoxygenase (5-LOX) in viral infections, such as influenzae and SARS, it remains unexplored in the pathophysiology of COVID-19. 5-LOX acts on free arachidonic acid (AA) to form proinflammatory leukotrienes (LTs). Of note, numerous cells involved with COVID19 (e.g., inflammatory and smooth muscle cells, platelets, and vascular endothelium) widely express leukotriene receptors. Moreover, 5-LOX metabolites induce the release of cytokines (e.g., tumour necrosis factor- $\alpha$ [TNF- $\alpha$ ], interleukin- $1 \alpha$ [IL$1 \alpha]$, and interleukin- $1 \beta[\mathrm{IL}-1 \beta]$ ) and express tissue factor on cell membranes and activate plasmin. Since macrophages, monocytes, neutrophils, and eosinophils can express lipoxygenases, activation of 5-LOX and the subsequent release of LTs may contribute to the severity of COVID-19. This review sheds light on the potential implications of 5-LOX in SARS-CoV2-mediated infection and the anticipated therapeutic role of 5-LOX inhibitors.
\end{abstract}

Keywords SARS-CoV-2 $\cdot$ COVID-19 $\cdot$ 5-lipoxygenase $\cdot$ CRS $\cdot 5$-LOX inhibitors

\begin{tabular}{|c|c|c|c|}
\hline \multicolumn{2}{|c|}{ Abbreviations } & \multirow{2}{*}{$\begin{array}{l}\text { ALI } \\
\text { PGs }\end{array}$} & \multirow{2}{*}{$\begin{array}{l}\text { Acute Lung Injury } \\
\text { Prostaglandins }\end{array}$} \\
\hline ACE2 & Angiotensin-Converting Enzyme 2 & & \\
\hline AKI & Acute Kidney Injury & $\operatorname{Ig}$ & Immunoglobulin \\
\hline $\mathrm{NP}+$ & Nucleoprotein Positive & ADE & Antibody-Dependent Enhancement \\
\hline FLAP & 5-Lipoxygenase Activating Protein & DAMPs & Damage-Associated Molecular Patterns \\
\hline $5-\mathrm{LOX} / \mathrm{LO}$ & 5-Lipoxygenase & IFN & Interferon \\
\hline $\mathrm{COX}$ & Cyclooxygenase & IL & Interleukin \\
\hline LT & Leukotriene & TNF & Tumour Necrosis Factor \\
\hline UPLC-MS & Ultra-high-Performance Liquid Chromatog- & NOS & Nitric Oxide Synthase \\
\hline & raphy-Mass Spectrometry & SARS & Severe Acute Respiratory Syndrome \\
\hline OxPL & Oxidized Phospholipid & MERS & Middle East Respiratory Syndrome \\
\hline & & $\mathrm{CoV}$ & Coronavirus \\
\hline \multicolumn{2}{|c|}{ Responsible Editor: John Di Battista. } & & spiratory Distress s \\
\hline & & & laney injury \\
\hline \multirow{3}{*}{\multicolumn{2}{|c|}{$\begin{array}{l}\text { Nohora Cristina Ayola-Serrano, Namrata Roy, Zareena Fathah and } \\
\text { Mohammed Moustapha Anwar have equally contributed to this } \\
\text { work. }\end{array}$}} & $\mathrm{CC}$ & Chemokine \\
\hline & & AA & Arachidonic Acid \\
\hline & & LA & Linoleic Acid \\
\hline \multicolumn{2}{|c|}{$\begin{array}{l}\triangle \text { Namrata Roy } \\
\text { drnamrata.2017@gmail.com }\end{array}$} & APCs & Antigen Presenting Cells \\
\hline \multicolumn{2}{|c|}{$\begin{array}{l}\square \text { Alfonso J. Rodriguez-Morales } \\
\text { alfonso.rodriguez@uam.edu.co }\end{array}$} & & \\
\hline
\end{tabular}




\section{Introduction}

In December 2019, the novel coronavirus disease 2019 (COVID-19) was first reported as the third lethal coronavirus outbreak [1], following the severe acute respiratory syndrome coronavirus (SARS-CoV) and the Middle East respiratory syndrome coronavirus (MERS-CoV) [2]. In September 2020, COVID-19 affected 216 countries [3], areas or regions with almost 29 million confirmed cases and about 922,000 deaths [4]. Characterised by crown-like glycoprotein spikes on their surface, coronaviruses belong to the family Coronaviridae [5] in the order of Nidovirales [6]. SARS-CoV-2 is a single, positive-stranded RNA (ssRNA) virus that causes cytokine release syndrome (CRS), leading to acute respiratory distress syndrome (ARDS), acute kidney injury (AKI), acute cardiac disorders, and liver dysfunction $[7,8]$. The current treatment of COVID-19 is mainly supportive; thus, there is a pressing need to find effective interventions [6]. In SARS-CoV-2-mediated ARDS, agents such as 5-lipoxygenase (5-LOX) inhibitors may reduce the virus-induced direct cytopathic effects, by immediate action on critical immune cells and mediators such as interleukin-6 (IL-6), which is associated with the inflammatory CRS in COVID-19 [7, 9]. Interestingly, 5-LOX inhibitors have cardiovascular (CV), neuronal, gastrointestinal (GI), kidney, cerebral, and vascular protective properties [10,11]. Recent reports have demonstrated that COVID-19 has affected such organs [12]. During the CRS in coronaviruses, higher levels of circulating tumour necrosis factor $\alpha$ (TNF- $\alpha$ ), IL-1 (Interleukin 1), IL-6, IL-8, IL-12, interferon $\gamma$ [IFN- $\gamma$ ], and transforming growth factor- $\beta$ (TGF- $\beta$ ), contribute to immune cell infiltration and multiorgan dysfunction [13-17]. SARS-CoV-2 is more contagious and is more likely to impact patients with comorbidities [18-20]. The earlier phase of both SARS-CoV and SARS-CoV-2 infections is commonly associated with acute lung injury (ALI) and the later stage is characterised by diffuse alveolar damage (DAD) with acute pneumoniae [16]. Herein, we hypothesise that using 5-LOX inhibitors in COVID-19 may help prevent the progression of the disease.

\section{Clinical manifestations and stages of COVID-19}

COVID-19 comprises 2 overlapping pathological subsets: the SARS-CoV-2 triggers the first subset, while the host response initiates the second one [21]. The following systematic model proposes the 3 distinct stages of COVID-19, which might enable appropriate therapeutic interventions.

\section{Stage 1: early stage of infection}

This stage involves an incubation period with mild symptoms, such as fever, fatigue, dry cough, eating disorder (i.e., anorexia), muscle pain, and sputum production, with less common symptoms (e.g., headache and rhinorrhoea). Approximately $81 \%$ of the cases are mild or asymptomatic [22]. In this phase, the SARS-COV-2 viral infection targets the lung with limited involvement of inborn immune mechanisms (i.e., innate immunity) [23]. More than $80 \%$ of non-survivors and critically-ill COVID-19 patients had an onset of progressive lymphopaenia or reduced lymphocyte blood count [24, 25]. A higher number of blood neutrophils (also called neutrophilia) contributes to the initiation and progression of pulmonary inflammation in later stages. In relation to SARS-COV-2, Blanco-Miguez et al., have identified 9 potential proinflammatory inducing peptides (PIPS) that may be linked to an increase in host inflammation [26] Neutrophil elastase (NE) (i.e., a cellular trap component) acts on these PIPS and showed homology against T-cell (T lymphocyte) epitopes only, suggesting that the underlying mechanism behind the viral proinflammatory response was $\mathrm{T}$ cell-related [27]. Furthermore, the enzymatic cleavage on the spike glycoproteins, the second most abundantly expressed transcript of the virus, produces $78 \%$ of these PIPS [28].

In response to SARS-CoV-2, neutrophils release inflammatory peptides, suggesting their association with the pulmonary strike [26]. Neutrophils accumulate early at the site of inflammation followed by a sustained population of monocytes, macrophages, and lymphocytes. Angiotensinconverting enzyme (ACE2) receptors mediate the SARSCoV-2 pathophysiology in the lungs, heart, and kidneys $[24,29]$. At this stage, the human body needs the adaptive immune response to halt the progression and limit the viral actions [21, 30]. Migration of neutrophils and activation of T-cell maintain immune homeostasis and prevent the hyper inflammatory responses [31]. Therefore, this article aims at examining early therapeutic intervention by mitigating the overactivated host inflammatory response to attenuate disease severity and prevent progression.

\section{Stage 2: the pulmonary stage (moderate-to-severe)}

During this stage, the host intrinsic immune system triggers a vigorous response upon the SARS-CoV-2 infection [23]. SARS-CoV-2 infiltrates the lung parenchyma and proliferate where patients develop viral pneumoniae with or without hypoxia [21, 24]. Here, the disease can progress from moderate-to-severe illness, with dyspnoea and a respiratory rate of $>22 / \mathrm{min}$ and $\mathrm{SPO}_{2}<94 \%$ to $>24 / \mathrm{min}$ and $\mathrm{SPO}_{2}<92 \%$ on room air. Computed tomography (CT) scan revealed 
bilateral infiltrates or ground-glass opacities 5-8 days at the onset of symptoms [24]. The host inflammatory response is activated with a declining viral load that postulates pulmonary involvement, leading to vasodilation, endothelial permeability, recruitment of leukocytes, hypoxaemia, and CV stress [24].

Severe COVID-19 causes 50\% of lung involvement, and histopathological data suggest pulmonary alveolar oedema, inducing laboured breathing and hyperplasia of pneumocytes [32]. Additionally, intestinal expression of ACE2 causes GI symptoms, such as diarrhoea, vomiting, and nausea. Cutaneous manifestations include vestibular eruptions on the trunk, acral erythema but with a mild disease course; in severe stages, livedo, necrosis, and acral ischaemia are associated with elevated D-dimer [33]. Mild symptoms of the central nervous system (CNS) include confusion and dizziness, while severe impairments comprise ataxia that is associated with encephalitis, skeletal muscle injury, and epilepsy, through ACE2 expression. This occurs by affecting the brainstem pathway and potential for transneural viral transmission [34]. In this review, the proposed inhibitor might alleviate neuroinflammatory disorders [35].

\section{Stage 3: systemic hyper inflammation stage}

In a small denomination of patients, pulmonary immunopathogenesis is exacerbated, and the host inflammatory response multiplies, leading to systemic hyper inflammation [24]. This exaggerated systemic inflammation can injure organs, especially those that have high ACE2 expressions on the intestine and kidneys. The damaged cells induce extreme inflammation in the lungs primarily mediated by the proinflammatory macrophages and granulocytes [30]. Tissue destruction leading to pulmonary systemic hyper inflammation is the leading cause of fatal respiratory disorders, requiring mechanical ventilation [21]. This advanced stage of acute illness is characterised by multiorgan failure and elevation of critical inflammatory biomarkers, procalcitonin, and D-dimer, whose elevation with lymphopaenia shows deteriorated consequence [24]. Elevated troponin-I and brain natriuretic peptide (BNP) levels are related to acute cardiac injury [36]. Non-survivors exhibit most of these biomarkers, including intravascular coagulation [22]. There is an overall reduced outcome with compromised immunity and comorbidities [24]. Vasoplegia, shock, and cardiopulmonary collapse manifest [21]. Highly elevated reactive protein (CRP) and ferritin levels, coagulopathy, AKI and abnormal liver function is evidence of macrophage activation syndrome kind of immunopathology, associated with type I interferon (IFN-1) responses and T cells hyperactivation [22, 37, 38]. Poor survival is noted in patients with elevated plasma levels of IL-6 is a critical biomarker that requires further investigations . Studies have shown that timing of anti-IL-6 has demonstrated an impact on tissue remodelling [22]. Albeit the risk of reactivating other respiratory infections and elevated liver enzymes, tociluzumab is currently being used. In this phase, judicial use of corticosteroids is made, while the consensus is to avoid them at early stages due to delayed viral clearance [21]. This review suggests that early mitigation of key mediators may cease progression towards multiorgan failure.

\section{Role of 5-LOX in SARS-CoV-2 infection}

Respiratory symptoms are the most common manifestations of SARS-COV-2 infection [38, 39]. The virus infects alveolar macrophages and the respiratory epithelium via ACE2 receptors, which are highly expressed in the lungs, heart, vascular endothelium, and gastrointestinal tract [39, 40]. Transmembrane protease serine 2 (TMPRS22) - a serine protease inhibitor found on various cells, especially the small intestine-has also been implicated in aiding viral entry [41, 42]. Current evidence suggests that macrophages play a vital role in the pathophysiology of COVID-19. SARS-COV-2 $\mathrm{NP}^{+} \mathrm{CD} 169^{+}$macrophages found in secondary lymphoid organs of COVID-19 patients suggests either direct uptake of the virus or virus-infected cells by the macrophages [38, 43]. Dysregulated iron metabolism in acute inflammation might contribute to 5-LOX-mediated activation of macrophages [43]. Cytolysis of infected cells triggers local inflammatory pathways, activating phospholipase A2 and releasing bioactive lipids [44].

The 5-LOX enzyme in association with the nuclear membrane 5-lipoxygenase activating protein (FLAP) acts on free arachidonic acid (AA) and leads to the formation of proinflammatory leukotrienes (LT). LTB4 is a potent monocytemacrophage and neutrophil chemoattractant, and is involved in T-cell migration and enhances dendritic cell activity and promotes their migration draining lymph nodes. It also increases the production of TNF- $\alpha$ and acts synergistically with IL-4 to activate B-cells (B lymphocyte). LTC4, LTD4, LTE4 induce tissue oedema, mucus secretion, and bronchoconstriction. LTA4 precursor is a potent eosinophil chemoattractant and induces neutrophil and monocyte migration and activation. 5-hydroxyeicosatetraenoic acid (5-HETE), an intermediate in the 5-LOX pathway, is a weak activator of neutrophils and eosinophils . LT receptors are widely distributed on inflammatory cells, smooth muscle cells, platelets, and vascular endothelium [9, 45-54].

Although 5-LOX is mainly expressed in myeloid cells like monocyte-macrophages, neutrophils, eosinophils and mast cells, synthesis of LT can occur in cells other than leucocytes, such as bronchial epithelial cells and fibroblasts. Receptors of LTB4 type 1 (BLT1) and type 2 (BLT2) are mainly expressed in leukocytes and spleen, respectively [49]. 
Receptors of LTC4, LTD4, and LTE4 (CysLTs) are shown in various cells like interstitial macrophages and respiratory epithelium. The expression of some of these enzymes and receptors involved in the synthesis of LT increases during acute inflammation $[9,47]$. Fang et al., suggested a close association between the expression of toll-like receptors (TLRs) and biosynthesis of LT in activated murine macrophages [46]. TLRs play an essential role in the activation of immune cells in response to an invading pathogen [50]. Moreover, Behrens et al., suggested that sustained TLR stimulation might lead to macrophage activation-like syndrome in mice models[51]. In addition, Wang et al., showed that LTB4 increased macrophage expression of inflammatory microRNAs via its action on the BLT1 receptor in murine models [55].

Activation of the cyclooxygenase (COX) pathway has an essential role in the development of inflammation. COX-1/ COX-2 pathways lead to the formation of prostaglandins (PG) like PGE2 and PGI2 (prostacyclin). Metabolites of the COX pathway are involved in various aspects of inflammation, including cytokine release, migration of leukocyte , increased vascular permeability, and fever. Thromboxane causes smooth muscle contraction and platelet aggregation. PGE2 increases the production of IL-6 by leukocytes and might be involved in viral pathogenesis [47].

In a subset of patients, rapid viral replication induces cell death and release of damage-associated molecular patterns (DAMPs), such as adenosine triphosphate (ATP), nucleic acids, and ASC oligomers. This triggers the activation of inflammasome and pyroptosis, leading to the recruitment of even more inflammatory cells $[41,56,57]$. The virus suppresses the release of IFN-1 in the early stages of infection by various mechanisms, hindering viral clearance by T-cells [57]. IFN- $\gamma$ is released after an initial delay and binds to IFN receptors on macrophages in the late phase of inflammation, recruiting more macrophages and releasing large amounts of proinflammatory cytokines [38, 39, 58]. The cytokine storm in COVID-19 is illustrated in Figs. 1 and 2.

Although the exact mechanism that SARS-CoV-2 employs to trigger the cytokine storm remains unknown, current preliminary reports and postmortem evidence suggest the widespread immune activation and the presence of high levels of cytokines IL-6, IL-7, IL-10, and TNF; chemokines CCL2, CCL3, CXCL10, and soluble IL-2 receptor [38].

A similar cytokine profile can also be observed in sepsis due to other infections. Namely, SARS-CoV-2 infection triggers an immune dysregulation in a subset of patients, which forms the crux of the cytokine surge, as previously observed in SARS and MERS infections. Similarly, SARSCoV-2 can also cause a cytokine surge [30, 59].

Intermediates of the LT and PG pathways (e.g., PGH2 and LTA4) undergo a complex mechanism of transcellular biosynthesis. This might provide an insight about how local inflammation expands into systemic involvement [47, 48, 60].

Regulation of 5-LOX is complex, since studies suggest that PGE2, IL-4, and IL-13 decrease the expression of 5-LOX in monocytes, in contrast to both IL-1 and IFN $\gamma$ [48]. A study conducted on human synovial fibroblasts and mice models suggested that 5 -LOX is involved in TNF- $\alpha$ induced cytokine release and that 5-LOX inhibitors inhibit the translocation of the nuclear factor- $\mathrm{KB}$ (NF-B) subunits p50 and p65 into the nucleus and decreased TNF- $\alpha$-induced IL- 6 and MCP-1 release [9]. Generation of TNF- $\alpha$ in the lungs is enhanced by LTB4 [47].

Bioactive lipids and their metabolites have been shown to promote virus propagation in other Ccoronaviruses. A study done using human coronavirus 229E (HCoV-229E) and UPLC-MS indicates that the linoleic acid (LA)-AA axis and their metabolites could be vital for understanding the pathophysiology of SARS-COV-2 [52, 61].

Several studies have documented lymphopaenia, thrombocytopaenia, increased neutrophil-to-lymphocyte ratio, a temporary increase in inflammatory indices likelactate dehydrogenase (LDH), CRP, ferritin-dimers, and coagulation abnormalities, to be more marked in severe COVID-19 patients as compared to milder cases. Levels of proinflammatory IL-6 significantly increased in critically-ill COVID19 patients, suggesting the possible role of hyper inflammation in the development of the other cellular abnormalities $[38,39]$.

Global T-cell lymphopaenia mainly involving $\mathrm{CD} 8^{+} \mathrm{T}$ cells was observed in severe SARS-CoV-2 infection . Currently, there is no evidence to suggest the direct invasion of T-cells by SARS-CoV-2. T-cell lymphopaenia may occur due to local recruitment, thereby reducing their levels in the systemic circulation [38]. Sustained high levels of inflammatory mediators might also play a role in depletion of lymphocytes [38, 39].

Upregulation of exhaustion markers such as natural killer $\mathrm{G} 2$ receptor (NKG2A) on $\mathrm{CD}^{+} \mathrm{T}$ and NK cells was observed in COVID-19 patients. This could indicate immune exhaustion due to severe sustained immune activation [25].

Weide et al., suggested that plasmin from the intrinsic coagulation pathway might be liable to stimulation of 5-LOX in humans [62]. Damage to vascular endothelial cells and activation of coagulation cascade by inflammatory mediators or direct cell damage by SARS-CoV-2 can lead to disseminated intravascular coagulation (DIC), such as intravascular coagulation observed in sepsis. Platelets play an essential proinflammatory role where plateletneutrophil aggregates are involved in the pathogenesis of ALI and sepsis [63]. The interactions between inflammation and coagulation might inflate the body's immune response 


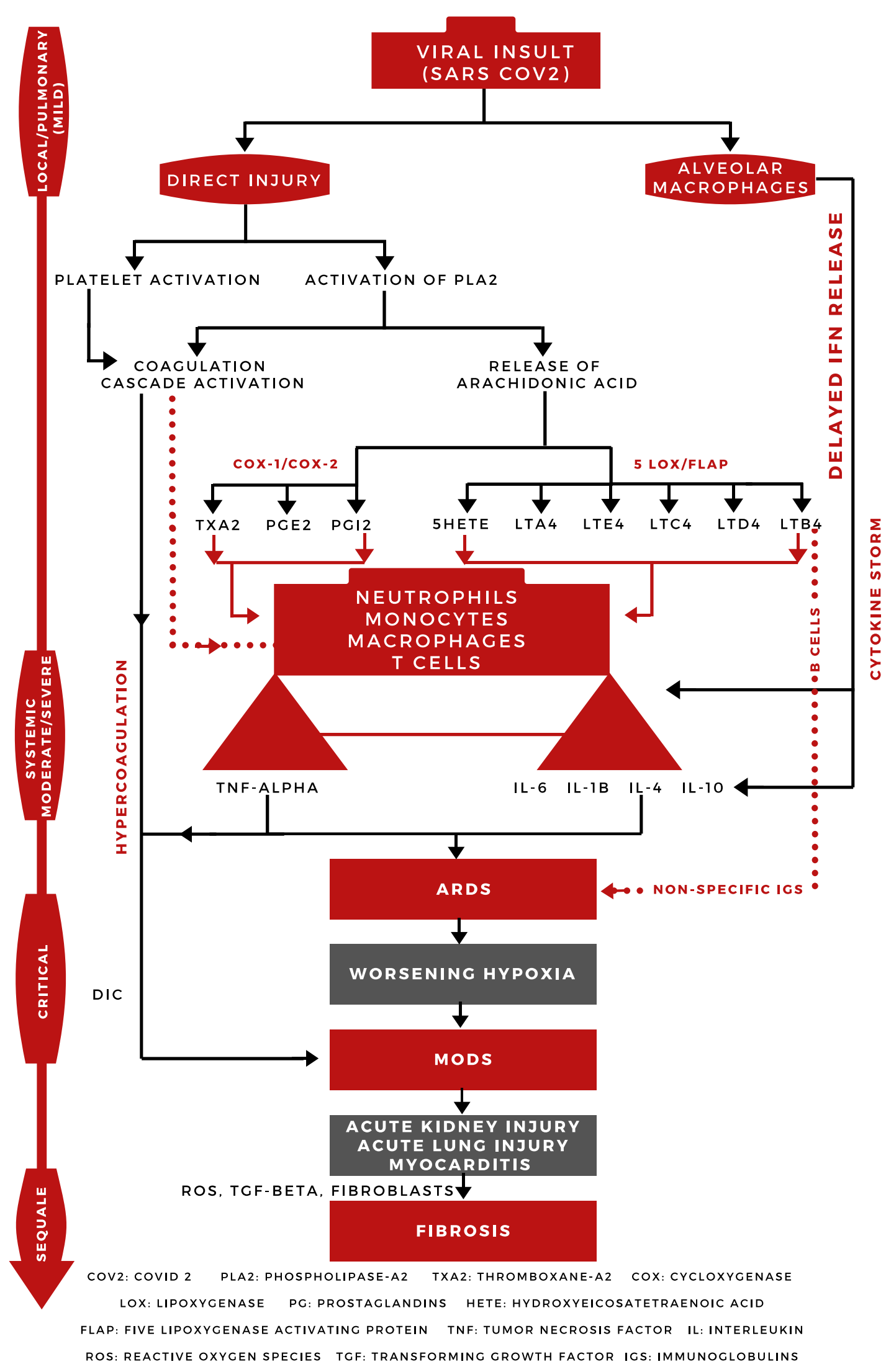

Fig. 1 An illustration of the cytokine storm in COVID-19 [38, 41, 56, 70, 114, 115] 
Fig. 2 A proposed model for the role of 5-LOX enzyme in the pathophysiology of COVID-19 $[48,93,116,117]$

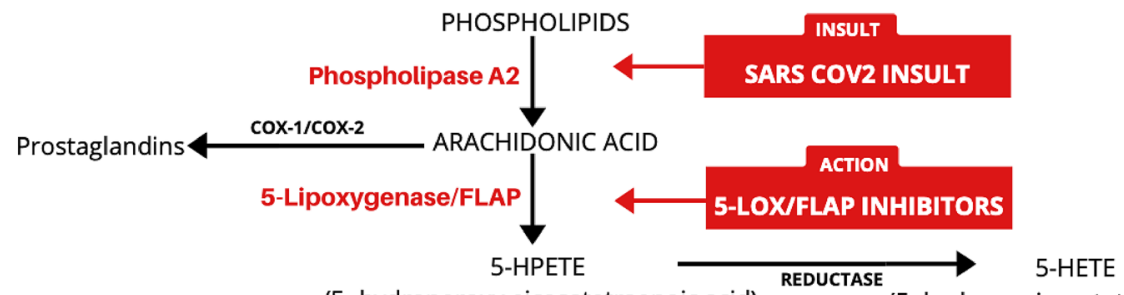

(5- hydroperoxy eicosatetraenoic acid)
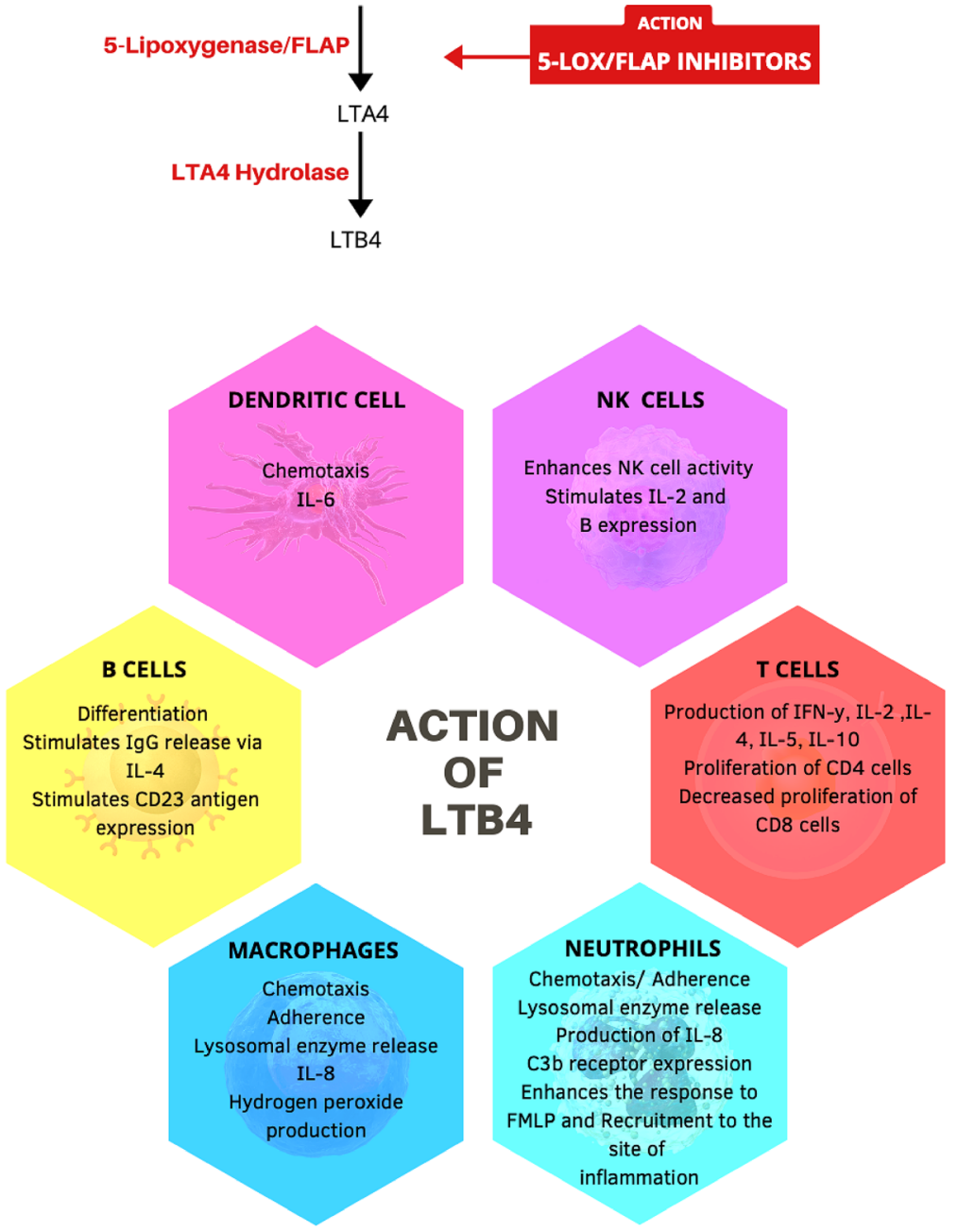

manifold and contribute to the increase in disease severity [25, 64-66].

Complement activation has been established as a cause of ARDS due to other diseases, but whether it is involved in the development of ARDS in COVID-19 is yet unclear [25, 67, 68]. Complements C3a and C5a activate the proinflammatory LOX pathway and may have a synergistic role in the development of eicosanoid surge and ARDS [69]. Recently, Risitano et al., showed widespread complement activation in lung biopsy from severe COVID-19 patients [67]. Several cells and metabolites of the inflammatory cascade can cleave C3 and C5, where C5a favours the pathway, leading to further recruitment of inflammatory cells and mediators [62]. Additionally, the sustained severe inflammation observed in cytokine storms prevents the body's immune resolution mechanisms, including resolvins and lipoxins from kicking in. Individuals who are deficient in lipoxins are more susceptible to develop severe pneumoniae due to other infections $[57,70]$.

The infiltrating inflammatory cells release reactive oxygen species (ROS) in a bid to clear the infection, leading to the production of oxidized phospholipids (OxPLs), which accumulate locally in the lungs. Furthermore, OxPLs lead to the recruitment of activated macrophages and release of TNF- $\alpha$ and IL- $1 \beta$ [45]. OxPLs were detected in the lungs of SARS-CoV patients, suggesting a similar mechanism to involve ALI in SARS-CoV-2 [38]. Destruction of alveolar macrophages by SARS-COV-2 leads to a pattern of lung 
injury observed in secondary alveolar proteinosis, accumulating fluid in alveolar spaces and worsening hypoxia [71]. In addition, innate and adaptive immune mechanisms eventually activate the humoural immune response. B-cells are activated through antigen-presenting cells (APCs), such as macrophages and dendritic cells along with PGs and LTs that possibly induce the production of non-neutralising antibodies. An increase in immunoglobulin G (IgG) antibody titer was associated with poor outcomes in SARS-CoV-2, facilitating the antibody-dependent viral entry into the cells, thereby accentuating viral damage. [25, 41]. Although the most commonly involved organ system is the respiratory system, involvement of the heart and kidneys have been reported in severe COVID-19 patients as well, but the exact mechanism is not yet well understood [20,72]. Collin et al., suggested that metabolites of 5-LOX might play an essential role in the development of multiple organ dysfunction by increasing the expression of adhesion molecules CD11b/ CD18 in murine models [73]. Microvascular thrombosis also contributes to organ injury and decline in organ functions [66].

Residual lung fibrosis has been one of the most severe sequelae observed in survivors of SARS-CoV infection [74, 75]. Although evidence of long-term sequelae in COVID19 is unavailable till present, given the close similarities between SARS-CoV and SARS-CoV-2, such sequelae might also be observed in survivors of severe SARS-CoV-2. Mechanical ventilation contributes to the development of lung fibrosis. Virus-induced hyper inflammatory reactionmediated activation of growth receptors and proliferation of fibroblasts might be implicated in lung fibrosis and other organs observed in survivors of SARS-CoV $[9,38,74]$. The LOX pathway might play a role in pulmonary fibrosis by direct or indirect activation of inflammation $[72,76]$.

Genetic variations in the host could also be responsible for the increased susceptibility and severity in specific individuals as compared to others, where a similar process was observed in SARS-CoV [77]. Based on the current treatment modalities employed in management of COVID-19, reducing viral loads using antivirals alone does not seem to prevent the worsening of disease severity and reduce mortality in severe COVID-19 cases. There are complex interconnections between the various pathways of inflammation, which are not completely understood $[7,78,79]$. It might be pertinent to consider the vital importance of 5-LOX and the LT pathway in this regard [80, 81]. McCarthy et al., demonstrated that using celecoxib, neuraminidase inhibitor, and aminosalicylate reduced the levels of IL- 6 and TNF- $\alpha$ and the mortality rate on $\mathrm{H}_{5} \mathrm{~N}_{1}$ infected mice [47]. There are strong reasons to consider that 5-LOX and metabolites of the LT pathway play an essential role in the extension of inflammation from local to systemic pathways. Moreover, it is reasonable to believe that disease progression, the development of systemic inflammation, and the involvement of organs such as the heart and kidneys, follow temporal progress [70]. Given this, we hypothesise that 5-LOX inhibitors could be used as as an adjuvant to the antiviral treatment as a novel combination in the management of COVID-19 [82]. Introducing such a regimen early in the disease course has the potential to prevent disease progression from mild-tosevere stage, avoid the development of CRS and multiorgan damage, long-term sequelae (e.g., lung fibrosis), and reduce both the need for mechanical ventilation and mortality in severe COVID-19 patients [76, 82].

\section{5-LOX and their roles in viral diseases}

Leukotrienes are lipid mediators that have a pivotal role in homeostasis and self-defence of the body [83]. Proinflammatory LT and antiinflammatory lipoxins are produced via the LOX pathway. They can be derived from AA, or eicosapentaenoic acid (EPA), or docosahexaenoic acid (DHA), with AA being the preferred substrate $[84,85]$. Several enzymes mediate the LOX pathway, including 5-LOX, 12-LOX, 12/15-LOX, 15-LOX type 2, 12(R)-LOX, and the epidermal LOX, where each number refers to the oxygen insertion position on AA [86].

Inflammatory signs associated with the recruitment of leukocytes to the site of infection are linked to the chemotactic effects of dihydroxy LTB4, which is a powerful stimulant of chemotaxis on several inflammatory cells, including T-cells, neutrophils, and dendritic cells [87]. Similarly, the sulfidopeptide LTC4 and LTE4 contribute to the inflammatory response by producing bronchoconstriction, smooth muscle contraction, and increased permeability of postcapillary venules, leading to airway oedema and enhanced secretion of viscous mucus [86, 88]. 5-LOX enzymes are involved in the rise and resolution of some inflammatory conditions because they have an essential role in the production of the specialised proresolving lipid mediators and proinflammatory LT [84].

The role of 5-LOX enzymes in the pathogenesis of several infections as well as allergic reactions is well established. For example, levels of 5-LOX and LTA4H in the airway are higher in patients with asthma than in those without asthma, with 5-LOX being the most potent LT to trigger the proinflammatory cascade. Moreover, the inhibition of 5-LOX might suppress the production of LTB4 [83]. Recently, 5-LOX inhibitors have been approved for the treatment of asthma [89]. Similarly, Shirey et al., concluded that targeting the 5-LOX pathway could hold possible therapeutic benefits against respiratory viral infections [88]. Importantly, LOX enzymes are involved in different phases of influenzae viral infection. Different levels of 5-LOX and 12/15-LOX were required in the pathogenic and resolution 
period, respectively. Clinically, disease severity and immune response were due to the increase in the 5-LOX-derived metabolites and the reduction of 12/15-LOX metabolites [81]. Furthermore, patients with influenzae infections exhibited higher levels of lipid mediators from the LOX pathway with elevated levels of cytokines and chemokines [81], suggesting that their levels are interrelated. Ebola virus has shown that levels of LOX enzymes rise within one hour, highlighting their role in the initial immune response [90].

The role of 5-LOX enzymes in the pathogenesis of lung injuries is unclear. Patients with pulmonary fibrosis show an increase in lung LTB4 and LTC4 levels, suggesting the constitutive activation of this pathway [91]. Coronavirus species has illustrated the vital activity of LOX enzyme as well as the downstream metabolites of AA via the LOX pathway in humans [52]. An increase in LTB4 is responsible for the increased neutrophil migration via chemotaxis to the lungs in SARS-CoV infections [92].

LTs are known to fuel local inflammation in various diseases. Targeted antiinflammatory drugs, especially 5-LOX inhibitors, may prove as crucial as antiviral drugs to modulate severe SARS-CoV-2 infections. The power of 5-LOX inhibitors in COVID-19 merits further investigations.s

\section{5-LOX inhibitors}

Arachidonic acid is the primary precursor of LTs that act as crucial promoters for cytokine release [93]. 5-LOX inhibitors limit the production of LTs, affecting the production of proinflammatory cytokines and their deleterious effects as well [94]. Recent studies (not peer-reviewed), directly link the action of 5-LOX in the lung tissue from COVID-19 deceased patients [95]. There is a growing body of evidence concerning the role of 5-LOX in COVID-19, which has been reported through this review. Presently, 5-LOX inhibitors have been widely explored as a treatment for several diseases, such as rheumatoid arthritis, lupus, and asthma, but not as a possible treatment for the hyper inflammatory states of COVID-19 [96]. 5-LOX inhibitors may be beneficial to halt the inflammatory cascade in its initial stages and prevent the progression to severe stages. We suggest that introducing 5-LOX inhibitors at the onset of the moderate stage of COVID-19, as illustrated by the CDC and the pulmonologists' international guidelines for the identification of phases of COVID-19, can reduce disease severity, prevent progression from moderate-to-severe and critical stages of COVID-19, and prevent the need for complex interventions. Subsequently, this would reduce the need for mechanical ventilation, expensive and difficult to obtain drugs, and the mortality rate in COVID-19 patients.

\section{Zileuton}

Zileuton - the only 5-LOX inhibitor approved by the FDAwas initially developed for asthma patients [94, 97]. It acts by chelating the active site of an iron component in the 5-LOX enzyme [97]. Zileuton showed promising results as a potential treatment for sepsis and other cytokine-associated conditions by reducing multiple organ injury and dysfunction in mice. Moreover, it reduced leukocyte infiltration into the lungs, one of the critical characteristics of COVID-19 $[73,98]$. Recent studies suggest that zileuton is not only a mild 5-LOX inhibitor in humans, but also causes hepatotoxicity, has troublesome dosing regimen, and has inappropriate pharmacokinetics/pharmacodynamics (PK/PD) profile [73, $96,97,99,100]$.

\section{PF-4191834}

PF-4191834 - primarily designed for pain and rheumatoid arthritis-is a novel non-redox selective 5-LOX potent inhibitor with a more adequate response in humans than that of zileuton. Studies demonstrated that PF-4191834 has the potential to provide all the benefits inhibiting 5-LOX in humans, making it a promising agent for COVID-19 [94, 96, 97]. Due to its low activity on COX-1 and COX-2 enzymes, it has shown little impact on pain management [95-97]. According to AdisInsight, Pfizer initiated phase II trials for patients with knee osteoarthritis; however, the study was terminated due to the potential risk-benefit of PF-4191834 that missed its primary target. It is imperative to reevaluate the risk assessment profile to be able to use PF-4191834 for the treatment of COVID-19 patient.

\section{Firazyr $^{\circledast}$ (Icatibant)}

Licensed in 37 countries, icatibant-a first-in-class highly selective competitive antagonist of bradykinin $\mathrm{B}_{2}$ receptoris indicated for the treatment of acute hereditary angioedema (HAE) attacks in adults and is resistant to degradation by bradykinin-cleaving enzymes [101-103]. COVID-19 binds to ACE2 to enter the host cells whose one of their activities is to hydrolyse the active bradykinin metabolite [desArg973] BK (DABK). Reducing the expression of ACE2 by the virus impairs the inactivation of DABK. This enhances its signalling through the bradykinin $\mathrm{B}_{1}$ receptor (BKB1R) that is highly inducible by inflammation, leading to fluid leakage and leukocyte recruitment to the lung. High levels of inflammatory mediators through the activation of the BK system may increase the risk of capillary permeability, ARDS, and multiple organ failure [104]. Inflammatory mediators such as TNF- $\alpha$, IL-4, $-6,-8$ and -13 via intracellular NF- $\mathrm{KB}$ and mitogen-activated protein kinase (MAPK) signal to induce the expression of bradykinin [105]. 
Selective BKB1R blocker could be a promising agent to prevent tissue inflammation and ARDS in COVID-19 [104, 106]. Icatibant has not been used in the control of the CRS in COVID-19 [107]. Administration of BKB1R antagonists in experimental models of sepsis has prevented haemodynamic derangement and attenuated the risk of multiorgan failure [104]. Blocking the production of bradykinin receptors may open a new potential therapeutic window for the treatment of COVID-19-induced ARDS, particularly before patients enter the irrevocable stages.

\section{5-LOX inhibitors under development}

BRP-187 has shown to be a potent inhibitor of LT biosynthesis in-vitro and in-vivo, by blocking 5-LOX/FLAP complex assembly in activated human monocytes and polymorphonuclear leukocytes (PMNs) and an inhibitor of the microsomal PGE2 synthase 1 [108, 109]. AM803 (currently known as GSK2190915) is a FLAP inhibitor that potently inhibits the formation of LTB4 and is currently under investigation in clinical trials [108].

The molecular structure of LOX and the complex nature of the involvement of LT in the initiation and resolution of inflammation, have not been yet clearly understood. This could be one of the reasons that several LOX inhibitors are not approved for clinical use [109]. Combination of 5-LOX/ LT inhibitors that can act on upstream or downstream mediators of the inflammatory pathways, can be used as an effective treatment option to abort acute inflammation in various diseases [110].

\section{Conclusions and recommendations}

Understanding the role of 5-LOX enzymes in the pathophysiology of COVID-19 enables clinical researchers to develop novel and more effective therapeutic strategies. Current treatment modalities employed in management of COVID19 aim at reducing viral loads [111], or simultaneously targeting 1 or 2 proinflammatory metabolites. For example, tocilizumab is a humanised monoclonal antibody that targets the IL-6 receptor . On the contrary, 5-LOX inhibitors act on the initial steps of inflammation;therefore, preventing the expression of multiple proinflammatory metabolites, such as ILs, TNF, and LTs. It is noteworthy to mention that 5-LOX enzymes are involved in numerous processes that intertwine to foment the hyper inflammatory states in SARS-CoV-2 infection, contributing to lung fibrosis, multiorgan failure, and ultimately death. More importantly, such inhibitory strategies should be adopted in parallel with maintaining an adequate inflammatory response for SARS-CoV-2 eradication. In-vitro and in-vivo mouse models should be carried out to test the efficacy of 5-LOX inhibitors, have an in-depth understanding of the role of 5-LOX enzymes and if there are possible crosstalk with other inflammatory pathways in COVID-19. This review has also shed light on potential 5-LOX inhibitors that have been developed in recent years, which might be the silver bullet against the deleterious effects of the hyper inflammatory states in COVID-19.

PGs, 5-LOX, LTs, and thromboxanes have proinflammatory actions but they are not the only molecules involved in the inflammatory cascade. The AA cascade and related metabolites show critical response in SARS-CoV-2-mediated pathophysiology and poor patient outcomes, including multiorgan failure and deaths. In addition to the inhibition of 5-LOX, we should direct our attention to further test the proinflammatory actions of other AA-related metabolites in COVID-19 (e.g., LTs, PGs, and thromboxanes). We should also investigate the potential antiinflammatory actions of derivatives of unsaturated fatty acids, including resolvins, lipoxins, maresins, and protectins, to augment the macrophage phagocytic capacity and to counteract the SARSCoV-2-mediated cytokine release and reduce the viral load $[112,113]$.

Acknowledgements This research was partially supported by CEMIC Mental Health Clinic; we thank the institution for its contribution.

Author contributions NCAS, NR, ZF, and MMA conceived the review, developed the preliminary search strategy, and drafted the manuscript. Rest of the authors refined the search strategy by conducting iterative database queries and incorporating new search terms; searched and collected the articles. RS, AJRM and KD conducted the quality assessment. All authors critically reviewed the manuscript for relevant intellectual content. All authors have read and approved the final version of the paper.

Funding CEMIC Mental Health Clinic, Cabrero Calle Real \#42-62, Cartagena, Colombia 13003.

Data availability The data that support the findings of this study are available from the corresponding author upon reasonable request.

\section{Declarations}

Conflict of interest All authors report no potential conflicts.

Ethical approval Approval was not required.

\section{References}

1. Dhama K, Khan S, Tiwari R, Sircar S, Bhat S, Malik YS, et al. Coronavirus disease 2019-COVID-19. Clin Microbiol Rev [Internet]. 2020;33:1-48.

2. Yang Y, Peng F, Wang R, Yange M, Guan K, Jiang T, et al. The deadly coronaviruses: The 2003 SARS pandemic and the 2020 novel coronavirus epidemic in China. J Autoimmun. 2020;109:102434 
3. Biscayart C, Angeleri P, Lloveras S, Chaves TDSS, Schlagenhauf $\mathrm{P}$, Rodríguez-Morales AJ. The next big threat to global health? 2019 novel coronavirus (2019-nCoV): What advice can we give to travellers? - Interim recommendations January 2020, from the Latin-American Society for Travel Medicine (SLAMVI). Travel Med Infect Dis. 2020;33:101567.

4. World Health Organization. Coronavirus disease (COVID-19) [Internet]. 2020 [cited 2020 Aug 9]. Available from: https://www. who.int/emergencies/diseases/novel-coronavirus-2019

5. Millán-Oñate J, Rodriguez-Morales AJ, Camacho-Moreno G, Mendoza-Ramírez H, Rodríguez-Sabogal IA, Álvarez-Moreno C. A new emerging zoonotic virus of concern: the 2019 novel Coronavirus (COVID-19). Infection. 2020;24:187-92.

6. Cascella M, Rajnik M, Cuomo A, Dulebohn SC, Di Napoli R. Features, Evaluation and Treatment Coronavirus (COVID-19) [Internet]. StatPearls. StatPearls Publishing; 2020 [cited 2020 Aug 9]. Available from: http://www.ncbi.nlm.nih.gov/pubmed/ 32150360

7. Liu J, Zheng X, Tong Q, Li W, Wang B, Sutter K, et al. Overlapping and discrete aspects of the pathology and pathogenesis of the emerging human pathogenic coronaviruses SARS-CoV, MERS-CoV, and 2019-nCoV. J Med Virol. 2020;92:491-4. https://doi.org/10.1002/jmv.25709.

8. Siordia JA. Epidemiology and clinical features of COVID19: a review of current literature. J Clin Virol [Internet]. 2020;127:104357.

9. Lin H-C, Lin T-H, Wu M-Y, Chiu Y-C, Tang C-H, Hour M-J, et al. 5-Lipoxygenase inhibitors attenuate TNF- $\alpha$-induced inflammation in human synovial fibroblasts. PLoS One [Internet]. 2014;9:e107890-e107890.

10. Manev H, Chen H, Dzitoyeva S, Manev R. Cyclooxygenases and 5-lipoxygenase in Alzheimer's disease. Prog Neuropsychopharmacol Biol Psychiatry [Internet]. 2011;35:315-9.

11. Martel-Pelletier J, Lajeunesse D, Reboul P, Pelletier J-P. Therapeutic role of dual inhibitors of 5-LOX and COX, selective and non-selective non-steroidal anti-inflammatory drugs. Ann Rheum Dis [Internet]. 2003;62:501-9.

12. Guzik TJ, Mohiddin SA, Dimarco A, Patel V, Savvatis K, Marelli-Berg FM, et al. COVID-19 and the cardiovascular system: implications for risk assessment, diagnosis, and treatment options. Cardiovasc Res [Internet]. 2020;116:1666-87. https://doi.org/10.1093/cvr/cvaa106.

13. Nicholls JM, Poon LLM, Lee KC, Ng WF, Lai ST, Leung CY, et al. Lung pathology of fatal severe acute respiratory syndrome. Lancet (London, England) [Internet]. 2003;361:1773-8.

14. Peiris JSM, Chu CM, Cheng VCC, Chan KS, Hung IFN, Poon LLM, et al. Clinical progression and viral load in a community outbreak of coronavirus-associated SARS pneumonia: a prospective study. Lancet (London, England) [Internet]. 2003;361:1767-72.

15. Zhang Y, Li J, Zhan Y, Wu L, Yu X, Zhang W, et al. Analysis of serum cytokines in patients with severe acute respiratory syndrome. Infect Immun [Internet]. 2004;72:4410-5.

16. Bradley BT, Bryan A. Emerging respiratory infections: the infectious disease pathology of SARS, MERS, pandemic influenza, and legionella. Semin Diagn Pathol [Internet]. 2019;36:152-9.

17. Yeung M-L, Yao Y, Jia L, Chan JFW, Chan K-H, Cheung K-F, et al. MERS coronavirus induces apoptosis in kidney and lung by upregulating Smad7 and FGF2. Nat Microbiol [Internet]. 2016;1:16004.

18. Su Z, Wu Y. A multiscale and comparative model for receptor binding of 2019 novel coronavirus and the implication of its life cycle in host cells. bioRxiv. 2020. https://doi.org/10.1101/2020. 02.20 .958272 .
19. Chen N, Zhou M, Dong X, Qu J, Gong F, Han Y, et al. Epidemiological and clinical characteristics of 99 cases of 2019 novel coronavirus pneumonia in Wuhan, China: a descriptive study. Lancet. 2020;395:507-13.

20. Li X, Ma X. Acute respiratory failure in COVID-19: is it "typical” ARDS? Crit Care [Internet]. 2020;24:198. https://doi.org/ 10.1186/s13054-020-02911-9.

21. Siddiqi HK, Mehra MR. COVID-19 illness in native and immunosuppressed states: a clinical-therapeutic staging proposal. J Hear Lung Transplant [Internet]. 2020;39:405-7.

22. $\mathrm{Wu} \mathrm{Z,} \mathrm{McGoogan} \mathrm{JM.} \mathrm{Characteristics} \mathrm{of} \mathrm{and} \mathrm{important} \mathrm{les-}$ sons from the coronavirus disease 2019 (COVID-19) Outbreak in China: Summary of a report of 72314 Cases from the Chinese Center for Disease Control and Prevention. JAMA. 2020;323:1239-42.

23. Mason RJ. Pathogenesis of COVID-19 from a cell biology perspective. Eur Respir J [Internet]. 2020;55:2000607.

24. Akhmerov A, Marbán E. COVID-19 and the heart. Circ Res [Internet]. 2020;126:1443-55.

25. Cao B, Wang Y, Wen D, Liu W, Wang J, Fan G, et al. A trial of lopinavir-ritonavir in adults hospitalized with severe covid-19. N Engl J Med [Internet]. 2020;382:1787-99.

26. Blanco-Miguez A, Sanchez B. Release of potential pro-inflammatory peptides from SARS-CoV-2 spike glycoproteins in neutrophil-extracellular traps. bioRxiv. 2020. https://doi.org/10. 1101/2020.05.02.072439.

27. Ong EZ, Chan YFZ, Leong WY, Lee NMY, Kalimuddin S, Haja Mohideen SM, et al. A dynamic immune response shapes COVID-19 progression. Cell Host Microbe [Internet]. 2020;27:879-82.

28. Kim D, Lee JY, Yang JS, Kim JW, Kim VN, Chang H. The architecture of SARS-CoV-2 transcriptome. Cell [Internet]. 2020;181:914-21.

29. Donoghue M, Hsieh F, Baronas E, Godbout K, Gosselin M, Stagliano $\mathrm{N}$, et al. A novel angiotensin-converting enzyme-related carboxypeptidase (ACE2) converts angiotensin I to angiotensin 1-9. Circ Res. 2000. https://doi.org/10.1161/01.res.87.5.e1.

30. Shi Y, Wang Y, Shao C, Huang J, Gan J, Huang X, et al. COVID19 infection: the perspectives on immune responses. Cell Death Differ [Internet]. 2020;27:1451-4.

31. Belkaid Y, Rouse BT. Natural regulatory T cells in infectious disease. Nat Immunol [Internet]. 2020;6:353-60.

32. Tian S, Hu W, Niu L, Liu H, Xu H, Xiao SY. Pulmonary pathology of early-phase 2019 novel coronavirus (COVID-19) pneumonia in two patients with lung cancer. J Thorac Oncol [Internet]. 2020;15:700-4.

33. Wollina U, Karada $\breve{g}$ AS, Rowland-Payne C, Chiriac A, Lotti T. Cutaneous signs in COVID-19 patients: a review. Dermatol Ther. 2020. https://doi.org/10.1111/dth.13549.

34. Werner C, Scullen T, Mathkour M, Zeoli T, Beighley A, Kilgore MD, et al. Neurological impact of coronavirus disease of 2019: practical considerations for the neuroscience community. World Neurosurg [Internet]. 2020;139:344-54.

35. Chu LS, Fang SH, Zhou Y, Yu GL, Wang ML, Zhang WP, et al. Minocycline inhibits 5-lipoxygenase activation and brain inflammation after focal cerebral ischemia in rats. Acta Pharmacol Sin [Internet]. 2007;28:763-72.

36. Arentz M, Yim E, Klaff L, Lokhandwala S, Riedo FX, Chong $\mathrm{M}$, et al. Characteristics and outcomes of 21 critically ill patients with COVID-19 in Washington State. JAMA. 2020;323:1612-4.

37. Batlle D, Soler MJ, Sparks MA, Hiremath S, South AM, Welling PA, et al. Acute kidney injury in COVID-19: emerging evidence of a distinct pathophysiology. J Am Soc Nephrol [Internet]. 2020;31:1380-3. 
38. Merad M, Martin JC. Author correction: pathological inflammation in patients with COVID-19: a key role for monocytes and macrophages. Nat Rev Immunol [Internet]. 2020;20:448.

39. Terpos E, Ntanasis-Stathopoulos I, Elalamy I, Kastritis E, Sergentanis TN, Politou M, Psaltopoulou T, Gerotziafas G, Dimopoulos MA. Hematological findings and complications of COVID -19. Am J Hematol [Internet]. 2020;95:14. https://doi. org/10.1002/ajh.25829.

40. Babapoor-Farrokhran S, Gill D, Walker J, Rasekhi RT, Bozorgnia B, Amanullah A. Myocardial injury and COVID-19: possible mechanisms. Life Sci [Internet]. 2020;253:5.

41. Tay MZ, Poh CM, Rénia L, MacAry PA, Ng LFP. The trinity of COVID-19: immunity, inflammation and intervention. Nat Rev Immunol [Internet]. 2020;20:363-74.

42. Liu C, Zhang X, Xiang Y, Qu X, Liu H, Liu C, et al. Role of epithelial chemokines in the pathogenesis of airway inflammation in asthma (Review). Mol Med Rep [Internet]. 2018;17:6935-41. https://doi.org/10.3892/mmr.2018.8739/abstract.

43. Dufrusine B, Di Francesco A, Oddi S, Scipioni L, Angelucci CB, D'Addario C, et al. Iron-dependent trafficking of 5-lipoxygenase and impact on human macrophage activation. Front Immunol [Internet]. 2019;10:1347. https://doi.org/10.3389/fimmu.2019. 01347/full.

44. Ebert R, Cumbana R, Lehmann C, Kutzner L, Toewe A, Ferreirós $\mathrm{N}$, et al. Long-term stimulation of toll-like receptor- 2 and -4 upregulates 5-LO and 15-LO-2 expression thereby inducing a lipid mediator shift in human monocyte-derived macrophages. Biochim Biophys Acta. 2020;1865:158702.

45. Poeckel D, Funk CD. The 5-lipoxygenase/leukotriene pathway in preclinical models of cardiovascular disease. Cardiovasc Res [Internet]. 2010;86:243-53.

46. Fang W-F, Douglas IS, Wang C-C, Kao H-C, Chang Y-T, Tseng $\mathrm{C}-\mathrm{C}$, et al. 5-Lipoxygenase activating protein (FLAP) dependent leukotriene biosynthesis inhibition (MK591) attenuates lipid A endotoxin-induced inflammation. PLoS One [Internet]. 2014;9:e102622.

47. McCarthy MK, Weinberg JB. Eicosanoids and respiratory viral infection: coordinators of inflammation and potential therapeutic targets. Mediators Inflamm. 2012;2012:236345.

48. Hedi H, Norbert G. 5-Lipoxygenase pathway, dendritic cells, and adaptive immunity. J Biomed Biotechnol. 2004;2004:99-105.

49. Yokomizo T. Two distinct leukotriene B4 receptors, BLT1 and BLT2. J Biochem [Internet]. 2015;157:65-71.

50. Pope RM, Huang QQ. The role of toll-like receptors in rheumatoid arthritis. Curr Rheumatol Rep [Internet]. 2009;11:357-64. https://doi.org/10.1007/s11926-009-0051-z.

51. Behrens EM, Canna SW, Slade K, Rao S, Kreiger PA, Paessler $\mathrm{M}$, et al. Repeated TLR9 stimulation results in macrophage activation syndrome: like disease in mice. J Clin Invest [Internet]. 2011;121:2264-77.

52. Yan B, Chu H, Yang D, Sze K-H, Lai P-M, Yuan S, et al. Characterization of the lipidomic profile of human coronavirus-infected cells: implications for lipid metabolism remodeling upon coronavirus replication. Viruses [Internet]. 2019;11:73.

53. Azkur AK, Akdis M, Azkur D, Sokolowska M, Veen W, Brüggen $\mathrm{M}$, et al. Immune response to SARS-CoV-2 and mechanisms of immunopathological changes in COVID-19. Allergy [Internet]. 2020;75:1564-81. https://doi.org/10.1111/all.14364.

54. Funk CD. Lipoxygenase pathways as mediators of early inflammatory events in atherosclerosis. Arterioscler Thromb Vasc Biol [Internet]. 2006;26:1204-6. https://doi.org/10.1161/01.ATV. 0000222960.43792.ff.

55. Wang Z, Filgueiras LR, Wang S, Serezani APM, Peters-Golden $\mathrm{M}$, Jancar S, et al. Leukotriene B 4 enhances the generation of proinflammatory microRNAs to promote MyD88-dependent macrophage activation. J Immunol [Internet]. 2014;192:2349-56.
56. Kumar V. Inflammasomes: pandora's box for sepsis. J Inflamm Res [Internet]. 2015;11:477-502.

57. Panigrahy D, Gilligan MM, Huang S, Gartung A, Cortés-Puch I, Sime PJ, et al. Inflammation resolution: a dual-pronged approach to averting cytokine storms in COVID-19? Cancer Metastasis Rev [Internet]. 2020;39:337-40. https://doi.org/10.1007/ s10555-020-09889-4.

58. Van Schaik SM, Tristram DA, Nagpal IS, Hintz KM, Welliver $\mathrm{RC}$, Welliver RC. Increased production of IFN- $\gamma$ and cysteinyl leukotrienes in virus- induced wheezing. J Allergy Clin Immunol [Internet]. 1999;103:630-6.

59. Delia RV, Harrison K, Oyston PC, Lukaszewski RA, Clark GC. Targeting the "Cytokine Storm" for therapeutic benefit. Clin Vaccine Immunol. 2013;20:319-27.

60. Sala A, Folco G, Murphy RC. Transcellular biosynthesis of eicosanoids. Pharmacol Rep. 2010;62:503-10.

61. Katze M, Korth M, Law GL, Nathanson N. Viral Pathogenesis 3rd Edition [Internet]. 3rd ed. Michael Katze, Marcus Korth, G. Lynn Law, Neal Nathanson, editors. Elsevier; 2016 [cited 2020 Aug 11]. Available from: https://www.elsevier.com/books/viralpathogenesis/katze/978-0-12-800964-2

62. Weide I, Römisch J, Simmet T. Contact activation triggers stimulation of the monocyte 5-lipoxygenase pathway via plasmin. Blood Am Soc Hematol. 1994;83:1941-51.

63. Yang Y, Tang H. Aberrant coagulation causes a hyper-inflammatory response in severe influenza pneumonia [Internet]. Cell. Mol. Immunol. Chinese Soc Immunology; 2016 [cited 2020 Aug 11]. p. 432-42. Available from: www.nature.com $/ \mathrm{cmi}$

64. Guo Y, Li J, Hagström E, Ny T. Beneficial and Detrimental Effects of Plasmin(ogen) during Infection and Sepsis in Mice. Chakravortty D, editor. PLoS One [Internet]. Public Library of Science; 2011 [cited 2020 Aug 11];6:e24774. Available from: https://dx.plos.org/https://doi.org/10.1371/journal.pone.0024774

65. Violi F, Pastori D, Cangemi R, Pignatelli P, Loffredo L. Hypercoagulation and antithrombotic treatment in coronavirus 2019: a new challenge. Thromb Haemost [Internet]. 2020;120:949-56. https://doi.org/10.1055/s-0040-1710317.

66. Connors JM, Levy JH. Thromboinflammation and the hypercoagulability of COVID-19. J Thromb Haemost [Internet]. 2020;18:1559-61. https://doi.org/10.1111/jth.14849.

67. Risitano AM, Mastellos DC, Huber-Lang M, Yancopoulou D, Garlanda C, Ciceri F, et al. Author Correction: Complement as a target in COVID-19? (Nature Reviews Immunology, (2020), 20, 6, (343-344), https://doi.org/10.1038/s41577-020-0320-7). Nat Rev Immunol [Internet]. 2020;20:448. https://doi.org/10.1038/ s41577-020-0331-4

68. Zilow G, Joka T, Obertacke U, Rother U, Kirschfink M. Generation of anaphylatoxin C3a in plasma and bronchoalveolar lavage fluid in trauma patients at risk for the adult respiratory distress syndrome. Crit Care Med [Internet]. 1992;20:468-73.

69. Markiewski MM, Lambris JD. The role of complement in inflammatory diseases from behind the scenes into the spotlight. Am J Pathol [Internet]. 2007;171:715-27.

70. Buckley CD, Gilroy DW, Serhan CN. Proresolving lipid mediators and mechanisms in the resolution of acute inflammation. Immunity [Internet]. 2014;40:315-27.

71. Italiani P, Boraschi D. From monocytes to M1/M2 macrophages: phenotypical vs. functional differentiation. Front Immunol [Internet]. 2014;5:514.

72. Peters-Golden M, Bailie M, Marshall T, Wilke C, Phan SH, Toews GB, et al. Protection from pulmonary fibrosis in leukotriene-deficient mice. Am J Respir Crit Care Med [Internet]. 2002;165:229-35. https://doi.org/10.1164/ajrccm.165.2.21040 50.

73. Collin M, Rossi A, Cuzzocrea S, Patel NSA, Di Paola R, Hadley $\mathrm{J}$, et al. Reduction of the multiple organ injury and dysfunction 
caused by endotoxemia in 5-lipoxygenase knockout mice and by the 5-lipoxygenase inhibitor zileuton. J Leukoc Biol [Internet]. 2004;76:961-70.

74. Venkataraman T, Frieman MB. The role of epidermal growth factor receptor (EGFR) signaling in SARS coronavirus-induced pulmonary fibrosis. Antiviral Res. 2017;143:142-50.

75. Zhang P, Li J, Liu H, Han N, Ju J, Kou Y, et al. Long-term bone and lung consequences associated with hospital-acquired severe acute respiratory syndrome: a 15-year follow-up from a prospective cohort study. Bone Res [Internet]. 2020;8:1-8. https://doi. org/10.1038/s41413-020-0084-5.

76. Montford JR, Bauer C, Dobrinskikh E, Hopp K, Levi M, WeiserEvans $M$, et al. Inhibition of 5-lipoxygenase decreases renal fibrosis and progression of chronic kidney disease. Am J Physiol - Ren Physiol [Internet]. 2019;316:F732-42.

77. Zhu X, Wang Y, Zhang H, Liu X, Chen T, Yang R, et al. Genetic variation of the human $\alpha$-2-Heremans-Schmid Glycoprotein (AHSG) gene associated with the risk of SARS-CoV infection. PLoS One [Internet]. 2011;6:e23730.

78. Turner MD, Nedjai B, Hurst T, Pennington DJ. Cytokines and chemokines: At the crossroads of cell signalling and inflammatory disease. Biochim Biophys Acta - Mol Cell Res. 2014; 1843:2563-82.

79. Abrial C, Grassin-Delyle S, Salvator H, Brollo M, Naline E, Devillier P. 15-Lipoxygenases regulate the production of chemokines in human lung macrophages. Br J Pharmacol [Internet]. 2015;172:4319-30. https://doi.org/10.1111/bph.13210.

80. Tschaikowsky K, Hedwig-Geissing M, Schiele A, Bremer F, Schywalsky M, Schüttler J. Coincidence of pro- and anti-inflammatory responses in the early phase of severe sepsis: longitudinal study of mononuclear histocompatibility leukocyte antigen-DR expression, procalcitonin, C-reactive protein, and changes in T-cell subsets in septic and postoperative patients. Crit Care Med [Internet]. 2002;30:1015-23.

81. Tam VC, Quehenberger O, Oshansky CM, Suen R, Armando AM, Treuting PM, et al. Lipidomic profiling of influenza infection identifies mediators that induce and resolve inflammation. Cell. 2013;154:213.

82. Haeggström JZ. Leukotriene biosynthetic enzymes as therapeutic targets. J Clin Invest [Internet]. 2018;128:2680-90.

83. Jo-Watanabe A, Okuno T, Yokomizo T. The role of leukotrienes as potential therapeutic targets in allergic disorders. Int J Mol Sci. 2019. https://doi.org/10.3390/ijms20143580.

84. Häfner AK, Kahnt AS, Steinhilber D. Beyond leukotriene formation-the noncanonical functions of 5-lipoxygenase. Prostaglandins Other Lipid Mediat. 2019. https://doi.org/10.1016/j.prost aglandins.2019.03.003.

85. O'Flaherty JT, Hu Y, Wooten RE, Horita DA, Samuel MP, Thomas MJ, et al. 15-Lipoxygenase metabolites of docosahexaenoic acid inhibit prostate cancer cell proliferation and survival. PLoS ONE. 2012;7:e45480.

86. Rådmark O, Werz O, Steinhilber D, Samuelsson B. 5-Lipoxygenase, a key enzyme for leukotriene biosynthesis in health and disease. Biochim Biophys Acta. 2015;1851:331-9.

87. Rask-Madsen J, Bukhave K, Laursen LS, Lauritsen K. 5-Lipoxygenase inhibitors for the treatment of inflammatory bowel disease. Agents Actions. 1992;36:C37-46.

88. Shirey KA, Lai W, Pletneva LM, Karp CL, Divanovic S, Blanco JCG, et al. Role of the lipoxygenase pathway in RSV-induced alternatively activated macrophages leading to resolution of lung pathology. Mucosal Immunol Nature Publishing Group. 2014;7:549-57.

89. Bruno F, Spaziano G, Liparulo A, Roviezzo F, Nabavi SM, Sureda A, et al. Recent advances in the search for novel 5-lipoxygenase inhibitors for the treatment of asthma. Eur J Med Chem. 2018;153:65-72.
90. Geisbert TW, Young HA, Jahrling PB, Davis KJ, Larsen T, Kagan E, et al. Pathogenesis of Ebola hemorrhagic fever in primate models: evidence that hemorrhage is not a direct effect of virus-induced cytolysis of endothelial cells. Am J Pathol. 2003; 163:2371-82.

91. Zeldin DC. The 5-lipoxygenase pathway: a new therapeutic target for the treatment of pulmonary fibrosis. Am J Respir Crit Care Med. 2002;165:146-7.

92. Hu W, Yen YT, Singh S, Kao CL, Wu-Hsieh BA. SARS-CoV regulates immune function-related gene expression in human monocytic cells. Viral Immunol. 2012;25:277-88.

93. Kumar V, Abbas A, Aster J, Robbins S. Robbins Basic Pathology - 9th Edition [Internet]. Elsevier; [cited 2020 Aug 9]. Available from: https://www.elsevier.com/books/robbins-basic-pathology/ kumar/978-1-4377-1781-5

94. Daniel Bouchette, Charles V. Preuss. Zileuton. xPharm Compr Pharmacol Ref [Internet]. Elsevier Inc.; 2007 [cited 2020 Aug 9]. p. 1-3. Available from: https://www.ncbi.nlm.nih.gov/books/ NBK448202/

95. Islam $1 \mathrm{R}$, Fische A. A transcriptome analysis identifies potential preventive and therapeutic 1 approaches towards COVID-19. 23 Rezaul Islam. Preprints [Internet]. MDPI AG; 2020 [cited 2020 Aug 9];1-21. Available from: www.preprints.org

96. Rainsford KD, Ying C, Smith F. Effects of 5-lipoxygenase inhibitors on interleukin production by human synovial tissues in organ culture: comparison with interleukin-1-synthesis inhibitors*. J Pharm Pharmacol [Internet]. 1996;48:46-52. https://doi. org/10.1111/j.2042-7158.1996.tb05875.x.

97. Masferrer JL, Zweifel BS, Hardy M, Anderson GD, Dufield D, Cortes-Burgos L, et al. Pharmacology of PF-4191834, a novel, selective non-redox 5-lipoxygenase inhibitor effective in inflammation and pain. J Pharmacol Exp Ther [Internet]. 2010;334:294-301. https://doi.org/10.1124/jpet.110.166967.

98. Singh VP, Patil C, Kumar M, Kulkarni S. Effect of 5-lipoxygenase inhibitor against lipopolysaccharide-induced hypothermia in mice. Indian J Exp Biol. 2006;43:1150-5.

99. Haynes J, Obiako B, King JA, Hester RB, Ofori-Acquah S. Activated neutrophil-mediated sickle red blood cell adhesion to lung vascular endothelium: role of phosphatidylserine-exposed sickle red blood cells. Am J Physiol Circ Physiol [Internet]. 2006;291:H1679-85. https://doi.org/10.1152/ajpheart.00256. 2006.

100. McMurray RW. Nonstandard and adjunctive medical therapies for systemic lupus erythematosus. Arthritis Care Res (Hoboken) [Internet]. 2001;45:86-100.

101. Fox RH, Goldsmith R, Kidd DJ, Lewis GP. Bradykinin as a vasodilator in man. J Physiol [Internet]. 1961;157:589-602.

102. Hock FJ, Wirth K, Albus U, Linz W, Gerhards HJ, Wiemer $\mathrm{G}$, et al. Hoe 140 a new potent and long acting bradykinin-antagonist: in vitro studies. Br J Pharmacol [Internet]. 1991;102:769-73.

103. Committee for Medicinal Products for Human Use - European Medicines Agency. Firazyr, INN-Icatibant acetate [Internet]. 2008. Available from: http://www.emea.europa.eu

104. Murugesan P, Jung B, Lee D, Khang G, Doods H, Wu D. Kinin B1 Receptor inhibition with BI113823 reduces inflammatory response, mitigates organ injury, and improves survival among rats with severe sepsis. J Infect Dis [Internet]. 2015;213:532-40. https://doi.org/10.1093/infdis/jiv426.

105. Ricciardolo FLM, Folkerts G, Folino A, Mognetti B. Bradykinin in asthma: Modulation of airway inflammation and remodelling. Eur J Pharmacol [Internet]. 2018;827:181-8.

106. Gobeil F, Sirois P, Regoli D. Preclinical pharmacology, metabolic stability, pharmacokinetics and toxicology of the peptidic kinin B1 receptor antagonist R-954. Peptides [Internet]. 2014;52:82-9. 
107. Qadri F, Bader M. Kinin B1 receptors as a therapeutic target for inflammation. Expert Opin Ther Targets [Internet]. 2018;22:3144. https://doi.org/10.1080/14728222.2018.1409724.

108. Garscha U, Voelker S, Pace S, Gerstmeier J, Emini B, Liening S, et al. BRP-187: a potent inhibitor of leukotriene biosynthesis that acts through impeding the dynamic 5-lipoxygenase/5-lipoxygenase-activating protein (FLAP) complex assembly. Biochem Pharmacol [Internet]. 2016;119:17-26.

109. Hu C, Ma S. Recent development of lipoxygenase inhibitors as anti-inflammatory agents. Medchemcomm [Internet]. 2018;9:212-25.

110. Mashima R, Okuyama T. The role of lipoxygenases in pathophysiology; new insights and future perspectives. Redox Biol [Internet]. 2015;6:297-310.

111. Rabaan AA, Al-Ahmed SH, Sah R, Tiwari R, Yatoo MI, Patel $\mathrm{SK}$, et al. SARS-CoV-2/COVID-19 and advances in developing potential therapeutics and vaccines to counter this emerging pandemic. Ann Clin Microbiol Antimicrob [Internet]. 2020;19:40.

112. Das UN. Can bioactive lipids inactivate coronavirus (COVID19)? Arch Med Res [Internet]. 2020;51:282-6.

113. Hoxha M. What about COVID-19 and arachidonic acid pathway? Eur J Clin Pharmacol [Internet]. 2020;76:1501-4.
114. Ye Q, Wang B, Mao J. The pathogenesis and treatment of the 'Cytokine Storm', in COVID-19'. J Infect [Internet]. 2020;80:607-13.

115. Liu PP, Blet A, Smyth D, Li H. The science underlying COVID19: implications for the cardiovascular system. Circulation [Internet]. 2020;142:68-78.

116. Norris V, Singh D, Boyce M, Kent S, Bentley J. Inhibition of the early asthmatic response to inhaled allergen by the 5-lipoxygenase activating protein inhibitor GSK2190915: a dose\&ndash;response study. Int J Gen Med [Internet]. 2013;6:897.

117. Joshi YB, Praticò D. The 5-lipoxygenase pathway: oxidative and inflammatory contributions to the Alzheimer's disease phenotype. Front Cell Neurosci [Internet]. 2015;8:436.

Publisher's Note Springer Nature remains neutral with regard to jurisdictional claims in published maps and institutional affiliations.

\section{Authors and Affiliations}

\section{Nohora Cristina Ayola-Serrano ${ }^{1} \cdot$ Namrata Roy $^{2}$ (1) $\cdot$ Zareena Fathah $^{3} \cdot$ Mohammed Moustapha Anwar $^{4}$. Bivek Singh ${ }^{5} \cdot$ Nour Ammar $^{6} \cdot$ Ranjit Sah $^{7} \cdot$ Areej Elba $^{6} \cdot$ Rawan Sobhi Utt $^{8} \cdot$ Samuel Pecho-Silva ${ }^{9,10,11}$. Alfonso J. Rodriguez-Morales ${ }^{9,11,12,13} \cdot$ Kuldeep Dhama $^{14} \cdot$ Sadeq Quraishi ${ }^{15}$}

1 CEMIC Mental Health Clinic, Cabrero Calle Real \#42-62, 13003 Cartagena, Colombia

2 SRM University, SRM Nagar, Kattankulathur, Chengalpattu, Tamil Nadu 603203, India

3 Kings College London, London, UK

4 Department of Biotechnology, Institute of Graduate Studies and Research (IGSR), Alexandria University, Alexandria, Egypt

5 Tongji University, Shanghai, China

6 Department of Pediatric Dentistry and Dental Public Health, Faculty of Dentistry, Alexandria University, Alexandria, Egypt

7 Department of Microbiology, Institute of Medicine, Tribhuvan University Teaching Hospital, Kathmandu, Nepal

8 Faculty of Medicine, Al Quds University, Jerusalem, Palestine
9 Master in Clinical Epidemiology and Biostatistics, Universidad Científica del Sur, Lima, Peru

10 Pneumology Service, Hospital Nacional Edgardo Rebagliati Martins, Lima, Peru

11 Latin American Network of COVID-19 Research, Pereira, Colombia

12 Grupo de Investigacion Biomedicina, Faculty of Medicine, Fundacion Universitaria Autonoma de Las Americas, Pereira, Risaralda, Colombia

13 School of Medicine, Universidad Privada Franz Tamayo (UNIFRANZ), Cochabamba, Bolivia

14 Division of Pathology, ICAR-Indian Veterinary Research Institute, Izatnagar, Bareilly, Uttar Pradesh 243122, India

15 Department of Anesthesiology \& Perioperative Medicine Tufts Medical Center, Tufts University School of Medicine, 800 Washington St, Ziskind 6038, Boston, MA 02111, USA 